\title{
PROJETO PILOTO: CONSIDERAÇÕES DE ALUNOS DO ENSINO FUNDAMENTAL SOBRE MÉTODO DE EDUCAÇÃO ALIMENTAR
}

\author{
Margareth Xavier da Silva ${ }^{1}$ \\ Joana Dias da Costa ${ }^{2}$ \\ Aki Uehara ${ }^{2}$ \\ Emília Cristina Benevides de Freitas ${ }^{3}$ \\ Anna Paola Trindade Rocha Pierucci ${ }^{4}$ \\ Cristiana Pedrosa Melo Porto 5
}

\begin{abstract}
RESUMO: A escola é considerada o espaço para desenvolvimento de vários saberes, dentre os quais, temas ligados à saúde. A adoção de práticas educativas com os escolares é necessária, pois as crianças vêm adquirindo o padrão alimentar dos adultos, com maior ingestão de alimentos ultraprocessados. Contudo, as atividades educativas devem ocorrer de forma participativa, a fim de favorecer o aprendizado e a adesão dos sujeitos ao conteúdo proposto, e esses sujeitos podem compartilhar suas opiniões a respeito da metodologia aplicada, por meio de grupos focais, técnica de coleta de dados em pesquisa qualitativa. Participaram desse estudo 125 estudantes matriculados no $3^{\circ}$ ao $5^{\circ}$ anos do Ensino Fundamental em um Centro Integral de Educação Pública, com idades entre oito e dez anos. Foram realizadas atividades para educação alimentar por meio de oficinas culinárias, gincanas e um lanche coletivo, utilizando-se material didático para a abordagem de temas ligados a grupos de alimentos e alimentação saudável. Os estudantes participaram de um grupo focal no final do projeto, o que possibilitou a oportunidade de exposição dos conteúdos desenvolvidos durante as oficinas e as gincanas. A maioria das turmas demonstrou ter obtido bom aproveitamento no que diz respeito ao aprendizado. Outros estudos relativos à importância da alimentação para a qualidade de vida poderão ser desenvolvidos com a participação de toda a escola.
\end{abstract}

PALAVRAS-CHAVE: Nutrição. Alimentação. Saúde. Aprendizado. Escolares.

\section{Pilot project: elementary school students' consideration about nutrition education method}

\begin{abstract}
A school is a place of knowledge development, which includes health related knowledge. The adoption of educational practices with students is necessary because children have been acquiring adults' dietary patterns, that include more ultra-processed food. Educational activities must occur in a participatory learning way in order to promote learning and adherence to the proposed content by the students, who can share their opinions about the methodology applied in focus groups, which is a data collection technique of qualitative researches. 125 students were part of the study; they were aged from eight to ten years old and were in the $3^{\text {rd }}, 4^{\text {th }}$ and $5^{\text {th }}$ grade of elementary school in a Public Education Integral Center. Aiming at nutritional education, culinary workshops, competition games and a collective snack were conducted.

\footnotetext{
Doutoranda em Nutrição pela Universidade Federal do Rio de Janeiro (margarethx@gmail.com).

2 Graduandas em Nutrição pela Universidade Federal do Rio de Janeiro (jodias01@gmail.com) (ueharaaki@hotmail.com).

${ }_{3}^{3}$ Mestre em Anatomia Humana pela Universidade Federal do Rio de Janeiro, professora do Departamento de Anatomia da Universidade Federal do Rio de Janeiro (emilia@icb.ufrj.br).

${ }^{4}$ Doutora em Ciência de Alimentos pela Universidade Federal do Rio de Janeiro, professora do Departamento de Nutrição Básica e Experimental da Universidade Federal do Rio de Janeiro (appierucci@gmail.com).

${ }^{5}$ Doutora em Química Biológica pela Universidade Federal do Rio de Janeiro, professora do Departamento de Nutrição Básica e Experimental da Universidade Federal do Rio de Janeiro (cristiana@nutricao.ufrj.br).
} 
Didactic materials were used to discuss topics related to food groups and healthy eating. At the end of the project, the students took part in a focus group, an opportunity for them to expose the contents developed during the workshops and competition games. Most of the groups had good results regarding learning. Further studies about the food importance to the quality of life may be developed including the whole school's participation.

KEYWORDS: Nutrition. Food intake. Health. Learning. Students.

\section{INTRODUÇÃO}

A escola é o segundo ambiente social na vida do indivíduo, sendo o primeiro a família. É considerada como o local ideal para atividades ligadas à saúde, incluindo programas de educação nutricional, consistindo em um espaço privilegiado para o desenvolvimento de vários saberes, pois os estudantes permanecem muitas horas do dia nesse ambiente, e lá estabelecem relações de amizade e de confiança, o que favorece a troca de conhecimentos (BRASIL, 1997; 2006).

Devido ao processo de transição nutricional que vem ocorrendo no Brasil, caracterizado pelo aumento da prevalência de obesidade, redução da desnutrição, ocasionadas por mudanças no padrão de consumo alimentar (CAMEJO et al., 2012), há a necessidade de adoção de práticas educativas com escolares que mostrem os benefícios de uma alimentação saudável, pois as crianças vêm adquirindo o padrão alimentar dos adultos, com maior ingestão de alimentos industrializados, ricos em gorduras saturadas ou trans, açúcares e sal, e estão desenvolvendo precocemente doenças crônicas não transmissíveis como obesidade, diabetes, dislipidemia e hipertensão (HALLAL et al., 2006; SUÑE et al., 2007).

Contudo, o processo educativo deve ocorrer de forma participativa através de atividades que poderão incentivar escolhas saudáveis (CONNORS, 2001; FREIRE, 2011). Os alunos não devem se sentir meros espectadores do conteúdo abordado, mas sim atores participativos, desenvolvendo consciência e responsabilidade por suas escolhas (FREIRE, 2011). Nesse caso, as oficinas culinárias podem favorecer o aprendizado e a conscientização a respeito dos alimentos saudáveis porque utilizam o sistema cognitivo, que envolve todos os sentidos: a visão, o olfato, a audição, o paladar e o tato, o que favorece a integração do escolar e a temática abordada (BIZZO; LEDER, 2005; CASTRO et al., 2007).

Entretanto, como a educação deve ser voltada para os educandos, é importante ouvir o que esses sujeitos pensam a respeito de programas educativos voltados para eles (FREIRE, 2011). Assim, as oficinas culinárias podem ser avaliadas por metodologia qualitativa, que permitirá a aproximação da população estudada e a compreensão dos significados que estes consideram importantes.

A metodologia qualitativa pode utilizar o grupo focal (CANESQUI, 2009; MINAYO, 2010) que é formado por dois subgrupos: o grupo dos pesquisadores e o dos sujeitos da pesquisa. Devem-se reunir os sujeitos em um ambiente que favoreça o desenvolvimento de um debate a respeito do objeto de estudo, o que se deseja conhecer. A intenção não é a de se chegar 
a uma ideia comum, mas de propiciar a troca de conceitos, para que cada participante acrescente considerações às que já traz consigo. Durante o grupo focal (GF), os pesquisadores desempenharão várias funções: a de moderador, que fará perguntas ao grupo e o estimulará o debate; a de observador, que anotará as reações dos sujeitos durante o GF e a do operador de áudio/vídeo, responsável pela gravação e registro de imagens durante todos os momentos, colhendo dados para análise posterior, quando todo material obtido será, então, integrado e avaliado. É necessário que haja a devida autorização por escrito dos participantes do GF para o uso de imagem e voz (MINAYO, 2010; SILVERMAN, 2009; GOMES; BARBOSA, 1999).

Nesse estudo, a metodologia utilizada foi qualitativa para se conhecer as considerações de estudantes de um Centro Integral de Educação Pública sobre atividades lúdicas - como oficinas culinárias e jogos -, e sobre a metodologia utilizada para educação alimentar, que pode ser avaliada pelos sujeitos envolvidos, os escolares, favorecendo, assim, a sua adesão, o que poderá contribuir na prevenção de doenças e promoção de saúde nesse grupo.

\section{MATERIAL E MÉTODOS}

Essa pesquisa obteve a aprovação do Comitê de Ética (IESC/UFRJ) e foi realizada de acordo com a Resolução n ${ }^{\circ}$ 196/96, do Conselho Nacional de Saúde, que regulamenta as práticas de pesquisas que envolvem seres humanos. O responsável por cada aluno também concedeu autorização escrita para a participação na pesquisa, incluindo direito do uso da voz e da imagem dos estudantes.

\section{Contato dos pesquisadores com a escola}

A equipe de pesquisa (EP) do Laboratório de Desenvolvimento de Alimentos para fins Especiais e Educacionais (DAFEE) foi composta por uma nutricionista, uma aluna de aperfeiçoamento de doutorado, uma aluna de aperfeiçoamento de mestrado e seis alunas de graduação do Instituto de Nutrição Josué de Castro, da Universidade Federal do Rio de Janeiro.

Um Centro Integral de Educação Pública (CIEP) no Rio de Janeiro foi selecionado para o campo da pesquisa, devido à localização geográfica, de acesso fácil acesso à EP, e por conter regularmente matriculados, alunos do $3^{\circ}$ ao $5^{\circ}$ anos, na faixa etária de oito a dez anos de idade.

Após o primeiro contato com diretora da escola, a EP participou de uma reunião com o corpo docente do CIEP, para apresentação do projeto, que foi aprovado para execução, sendo estabelecida a data para o início das atividades propostas. 


\section{Público-alvo}

Quatro turmas com alunos de $3^{\circ}, 4^{\circ}$ e $5^{\circ}$ anos do Ensino Fundamental de Centro Integral de Educação Pública, com idades entre oito e dez anos, totalizando 125 estudantes, sendo 48,75\% do gênero masculino ( $\mathrm{n}=61$ alunos) e $51,25 \%$ do feminino ( $\mathrm{n}=64$ alunas).

\section{Critérios de inclusão}

Todos os alunos das turmas que participaram da pesquisa fizeram parte das atividades propostas, por se tratarem de eventos educativos, não invasivos e que utilizaram métodos lúdico-didáticos.

\section{Atividades educativas com os escolares}

As atividades educativas realizadas com os alunos incluíram oficinas culinárias, atividades informativas, gincanas e um lanche coletivo.

a. Oficinas culinárias

As turmas participaram de quatro oficinas de culinária. Os critérios para a escolha das preparações, pela EP, foram: facilidade na elaboração, adequadas a lanche, de baixo custo e que contivessem frutas e hortaliças com o aproveitamento integral das mesmas, sempre que possível.

As oficinas ocorriam uma vez por semana e tiveram a duração de uma hora. A professora, responsável pela turma, permanecia no refeitório durante todo o evento, acompanhando seus alunos.

Os alunos receberam touca, higienizaram as mãos e sentaram-se em volta da mesa do refeitório, que estava previamente organizada com todo o material necessário. Utilizouse como material didático, uma pirâmide tridimensional, colorida e plastificada, cujo tamanho permitia a visualização por toda a turma.

Para iniciar a atividade culinária, cada ingrediente da receita foi mostrado à turma, para que o denominasse e o localizasse na pirâmide alimentar. Os ingredientes foram colocados em um recipiente pela nutricionista, que passava por cada escolar para manipulação, com a ajuda da EP. Após as oficinas, enquanto os alunos aguardavam a cocção e o resfriamento das preparações para degustação, ocorreram outras atividades, das quais duas foram informativas e duas, gincanas. 
b. Atividades Informativas

As atividades informativas empregaram, como materiais didáticos, a pirâmide alimentar já conhecida das oficinas culinárias, e o cartaz validado pelo GRUPO DAFEE, durante pesquisa (SILVA, 2010), denominado: "Alimentos: de onde vêm, o que são e o que contém". Esse cartaz mostrava figuras relacionadas à origem dos alimentos, como são comercializados e quais seus principais nutrientes. As turmas também participaram de gincanas, após as duas últimas oficinas culinárias do projeto.

c. Gincanas

As gincanas ocorreram da seguinte forma: cada turma foi dividida em quatro grupos; cinco cartazes foram colados na frente da sala, sendo um com desenho de uma pirâmide alimentar vazia, sem os nomes dos grupos de alimentos, e os outros quatro cartazes com um prato vazio com o título "prato saudável".

Iniciou-se a gincana com o jogo da pirâmide, em que cada grupo recebeu da EP um envelope contendo oito figuras, recortadas de encartes de supermercados, para colar na pirâmide alimentar, cada uma representando um grupo de alimentos. Cada grupo foi chamado ao quadro para colar as gravuras e receberam a pontuação, sendo um ponto para cada acerto. Logo após o término da colagem na pirâmide alimentar, iniciava a gincana do prato saudável. Foi distribuído para cada grupo um envelope com oito gravuras, havendo a orientação de escolha das figuras que considerassem saudáveis para uma grande refeição (almoço ou jantar) e descarte das figuras de alimentos não saudáveis. Os grupos procederam, um de cada vez, a colagem das gravuras escolhidas no prato saudável. A pontuação final foi o resultado da soma dos dois jogos (pirâmide e prato). Cada componente do grupo vencedor recebeu como prêmio uma cartela de adesivos com frutas ou hortaliças. Os alunos participaram da degustação em suas salas de aula. Foi oferecido o produto da oficina do dia a cada um, que podia se servir da porção já fracionada. A professora da turma também participou da degustação.

\section{Atividades para avaliar o aprendizado e a aceitação dos escolares}

Como intuitode avaliaro aprendizado e aceitação dos escolares, foram realizadas as seguintes atividades:

a. Lanche coletivo

Um mês após a última oficina culinária, ocorreu o lanche coletivo. As turmas foram divididas em grupos de quatro alunos e foi proposto a cada grupo que trouxesse para escola uma preparação, considerada saudável, para ser dividida com os colegas no refeitório da escola. O evento foi filmado e gravado para análise dos resultados obtidos, para se avaliar o que os alunos consideraram como alimentos saudáveis. A filmagem e a gravação foram previamente autorizadas por escrito, pelos responsáveis pelos escolares. 
O lanche coletivo foi uma atividade que, além de educativa, serviu para avaliação do aprendizado dos alunos pela EP.

\section{b. Grupo focal}

Uma semana após o lanche coletivo, ocorreu o Grupo Focal. Foram escolhidos de três a quatro alunos das quatro turmas participantes, totalizando catorze alunos, sendo metade de cada gênero. O GF, que aconteceu em uma sala da própria escola, teve a duração de uma hora e contou com a participação da EP (um mediador, um observador e um operador de áudio e vídeo). Aos alunos participantes das oficinas culinárias, o mediador pediu que descrevessem o que ocorreu durante essas oficinas. Depois, fez perguntas estruturadas aos alunos: "O que vocês acharam das oficinas culinárias?"; "O que são alimentos saudáveis?”.

\section{RESULTADOS E DISCUSSÃO}

\section{Oficinas e atividades informativas}

Durante as oficinas, os alunos tiveram facilidade em identificar e correlacionar, na pirâmide alimentar, os ingredientes das receitas. As atividades informativas ocorreram após as duas primeiras oficinas culinárias. Nesses eventos, os alunos conseguiram identificar as figuras na pirâmide alimentar e no pôster, contudo, demonstraram dúvida quanto à figura do açúcar mascavo, denominando-o como café. Posteriormente, esse produto foi oferecido para degustação na última oficina culinária em que seria ingrediente na preparação do bolo de banana para que todos o provassem, favorecendo o conhecimento de suas características sensoriais e fosse, assim, elucidada a diferença entre o açúcar refinado e o mascavo.

A participação dos escolares nas oficinas e atividades informativas proporcionou a integração das práticas educativas, possibilitando o contato com o tema alimentação de maneira divertida e prazerosa (CASTRO et al., 2007).

As gincanas obtiveram empate com as turmas do $3^{\circ}$ (dois eventos) e $4^{\circ}$ (um evento) anos. Como critério para desempate, procedeu-se a utilização de uma figura de lasanha, preparada com camadas alternadas de massa, carne, queijo e algum tipo de molho. A partir dessa figura, os grupos deveriam compor um prato saudável. Ganhou a equipe que escolheu salada de hortaliças para composição do prato.

Os grupos de alunos que venciam as gincanas sempre eram premiados com cartela de adesivos de frutas e hortaliças, porém, na última competição, todos foram premiados, por ser a última atividade com a oficina e gincana. A adaptação das orientações para o público escolar com o qual foram desenvolvidas as atividades educativas, considerando-se o contexto social e político em que ocorreram, foi importante para a adesão dos sujeitos às propostas durante o projeto (COSTA; RIBEIRO; RIBEIRO, 2001). 


\section{Lanche coletivo}

O lanche coletivo foi realizado no refeitório escolar no período matutino e os alunos trouxeram frutas, biscoito de polvilho, sanduíche de pão de forma integral com atum e cenoura ralada, sanduíche de pão de forma branco com queijo, presunto, tomate e alface, iogurte, bebida à base de soja e suco de frutas para partilharem com a turma.

Foi perguntado aos grupos o porquê das escolhas dos alimentos que trouxeram nesse dia: fruta, "Porque é saudável"; biscoito de polvilho, "Era o que eu tinha em casa, mais saudável do que o Fandango"; iogurte, "Porque é saudável"; "Qual o lugar do iogurte na pirâmide?" "Nos laticínios"; sanduíche com atum e cenoura, "O pão é dos cereais e o recheio: atum, lá (apontando para o grupo das carnes)"; sanduíche com presunto, queijo e hortaliças: "O pão nos cereais, o queijo nos laticínios e o alface e tomate nas verduras (apontando para o grupo das hortaliças)”. As respectivas professoras ficaram presentes durante todo o tempo destinado ao lanche coletivo.

A aprendizagem pode ocorrer não apenas no ambiente escolar, mas em várias situações vivenciadas, que abrangem hábitos, aspectos da vida afetiva, assimilação de valores culturais, e resulta de toda estimulação do ambiente recebida pelo indivíduo durante a vida e, também, ao sofrer interferências intelectuais, psicomotora, física e social (PINTO; TAVARES, 2010), tornando-se significativa quando há a correlação entre o conteúdo aprendido e sua aplicabilidade na vida do sujeito.

Os estudantes demonstraram ter aprendido os conteúdos sobre alimentos e alimentação saudável, desenvolvidos durante as atividades propostas, pois trouxeram para o lanche alimentos pouco industrializados, com frutas e hortaliças como ingredientes, e os correlacionaram corretamente na pirâmide alimentar. Dentro desse contexto, demonstrou-se a possibilidade do uso da atividade lúdico-didática na aprendizagem, como elemento fundamental no processo de apropriação do conhecimento (FERNANDES, 2012).

\section{Grupo focal}

Foram desenvolvidos dois grupos focais, em uma sala da escola, com catorze alunos escolhidos aleatoriamente dentre as turmas que participaram da pesquisa. Durante o evento, a maioria das crianças demonstrou dificuldade em estabelecer um debate a respeito das questões propostas e limitava-se apenas a responder ao que estava sendo perguntado. Segue a descrição de algumas das falas dos alunos que expressaram a ideia central dos do grupo, categorizadas por assunto, que foi desenvolvido durante a reunião. Segundo Silverman (2009), é preciso que se observe como conceitos são construídos nas interações entre os componentes do GF, pois a principal característica dessa técnica é o aprofundamento em algum objeto de estudo, por meio da expressão verbal de seus participantes, permitindo que eles exibam, simultaneamente, suas considerações e compreensões a respeito de determinado tema. 


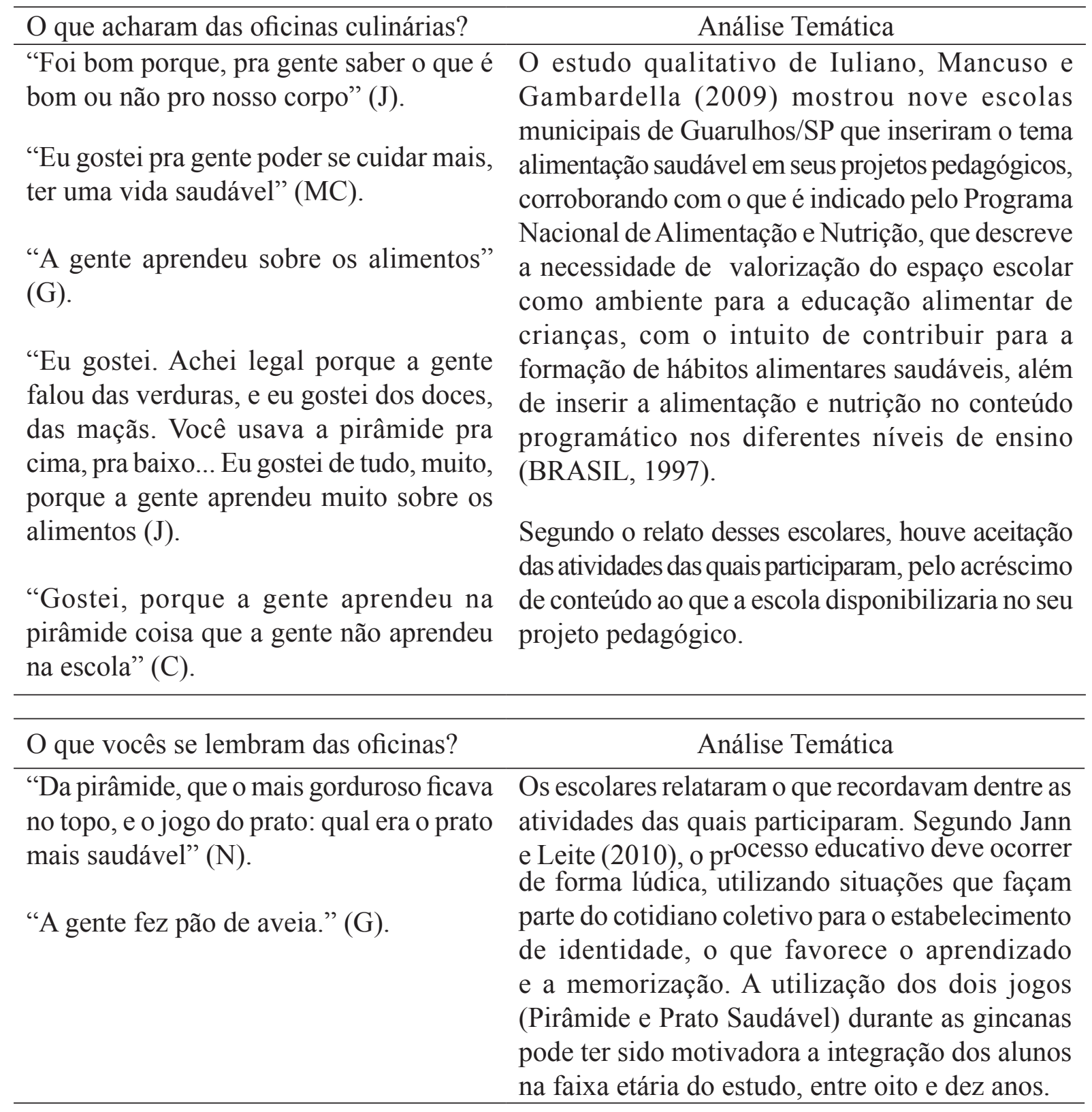




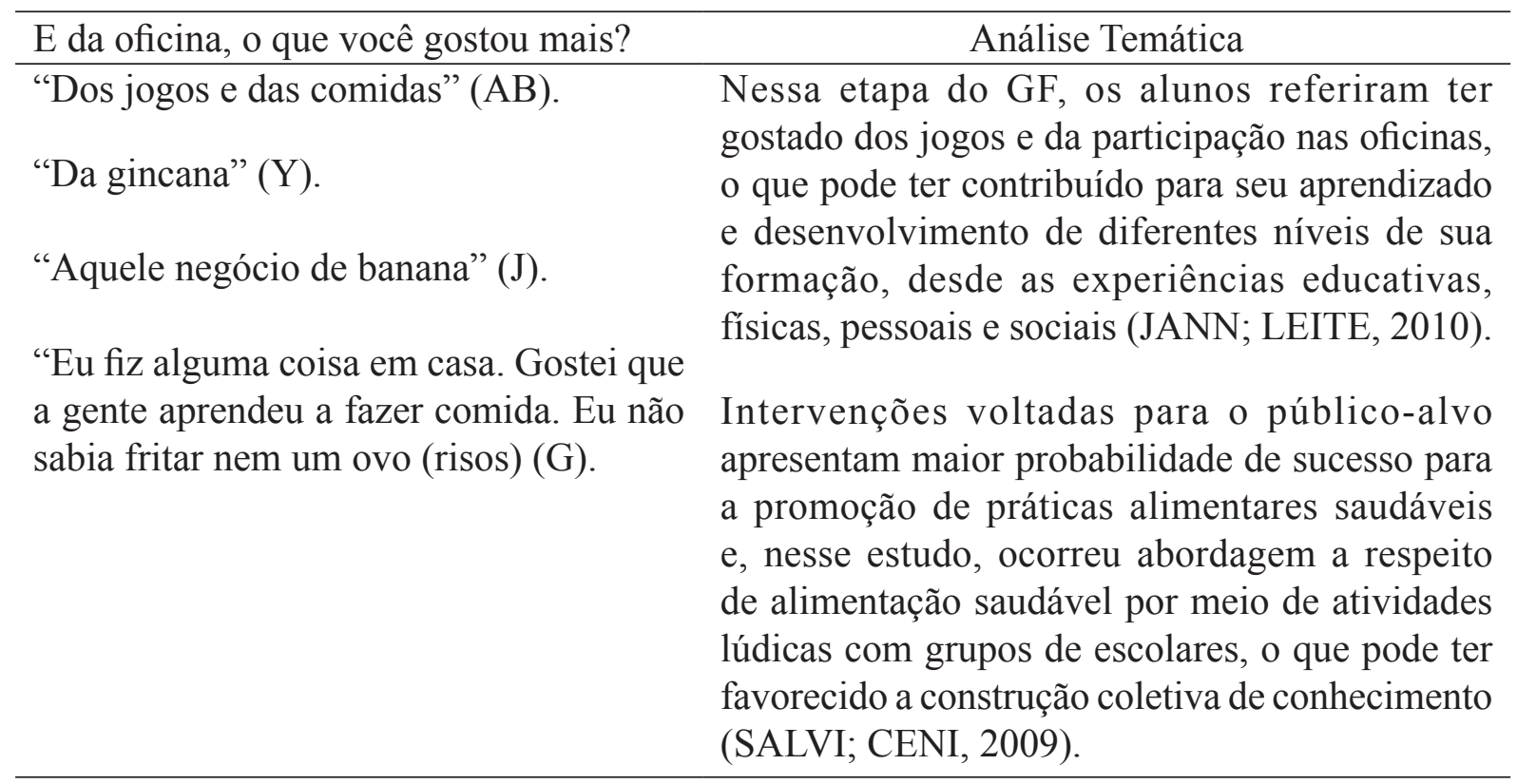

\begin{tabular}{|c|c|c|}
\hline O que é saudável? & $\begin{array}{c}\text { E o que não é } \\
\text { saudável? }\end{array}$ & Análise Temática \\
\hline $\begin{array}{c}\text { "O que é bom pro } \\
\text { corpo" (R). } \\
\text { "Espinafre, maçã, } \\
\text { frango" (G). } \\
\text { "Pode-se comer } \\
\text { de tudo, como } \\
\text { mostrou na } \\
\text { pirâmide, desde } \\
\text { que seja com } \\
\text { moderação" }(\mathrm{M}) .\end{array}$ & $\begin{array}{l}\text { "Chocolate" (N). } \\
\text { "Salgados" (L). } \\
\text { "Coxinha, } \\
\text { salgados com } \\
\text { salsicha. Vem com } \\
\text { muito óleo" (V). } \\
\text { "Rissole" (N). }\end{array}$ & $\begin{array}{l}\text { Em um estudo de Toral, Conti e Slater (2009), } \\
\text { em que realizaram GF entre adolescentes, com } \\
\text { idades entre } 10 \text { e } 19 \text { anos, para que qualificassem } \\
\text { alimentos saudáveis e, houve, dentre as falas, } \\
\text { similaridade com os conceitos desse estudo, já que } \\
\text { também destacaram a necessidade de se ter uma } \\
\text { participação reduzida de guloseimas, alimentos } \\
\text { industrializados e fast-food. } \\
\text { O estudo de Freitas colaboradores (2013) realizou } \\
\text { entrevistas com escolares da rede pública do } \\
\text { Ensino Fundamental na Bahia e, na discussão sobre } \\
\text { alimentos saudáveis, as respostas corroboram com } \\
\text { os estudantes desse estudo que referiram que não } \\
\text { se deve comer fritura por causa do colesterol, } \\
\text { conceituando correta a ingestão de alimentos como } \\
\text { feijão e verduras. } \\
\text { Não foi encontrado, na literatura, GF com alunos } \\
\text { na faixa etária desse estudo, talvez pela dificuldade } \\
\text { de se estabelecer um debate entre crianças. O } \\
\text { grupo de escolares demonstrou conceitos a } \\
\text { respeito de alimentação saudável e não saudável, } \\
\text { de acordo com o conteúdo abordado durante a } \\
\text { intervenção, baseado no Guia Alimentar para a } \\
\text { população brasileira (BRASIL, 2005). }\end{array}$ \\
\hline
\end{tabular}


O compartilhamento de conhecimento entre os estudantes no ambiente escolar beneficiou a discussão das situações do cotidiano alimentar e a importância de escolhas conscientes, o que poderá resultar em mudança no comportamento alimentar, embora avaliação em longo prazo não tenha sido feita (COSTA; RIBEIRO; RIBEIRO, 2001). Em intervenções nutricionais, o foco central costuma ser a difusão de informações sobre os benefícios de determinados alimentos e nutrientes e os malefícios de outros (CASTRO et al., 2007).

Propostas educativas em nutrição com atendimentos em grupo objetivam tornar o ambiente interativo e facilitador de aprendizagem. Por meio do trabalho em equipe, é possível observar uma crítica reflexiva dos envolvidos, com a possibilidade de mudança de hábitos, propondo uma melhor qualidade de vida (TCHAKMAKIAN, 2002). Os resultados deste estudo revelaram a valorização dos benefícios em escolhas alimentares saudáveis.

Considerando que a adoção de um estilo de vida saudável deve ocorrer desde a infância e a adolescência, compreender as percepções dos jovens sobre uma alimentação saudável é fundamental para o delineamento adequado de materiais educativos e intervenções nutricionais (GELLAR, 2007). Deve ser considerado que a mudança do comportamento alimentar do adolescente somente será alcançada quando este perceber sentido em sua história de vida, englobando o individual e o social, a emoção e a ação (RODRIGUES; BOOG, 2006).

Neste estudo, optou-se pela técnica de GF devido às vantagens oferecidas por este método, quanto à formação de um ambiente propício para um debate informal entre os participantes, no qual são compartilhados sentimentos, entendimentos, experiências e conhecimentos. Trata-se de uma forma ideal para exploração das atitudes e percepções dos adolescentes no ambiente social em que foram construídas (STEVENSON et al., 2007).

A elaboração e o uso de materiais educativos em saúde deve se pautar no debate entre os significados e na valorização de experiências entre os responsáveis pelas intervenções e os integrantes do grupo alvo. O diálogo crítico, que possibilita um processo comunicativo aberto, permitiu identificar interesses em comum entre os adolescentes e os responsáveis pela estratégia educativa, permitindo uma intervenção nutricional fundada na promoção da saúde e no alcance concreto dos objetivos esperados (KELLY-SANTOS; ROZEMBERG, 2006).

Os alunos demonstraram conhecimento dos conceitos desenvolvidos durante as atividades na escola, embora a verbalização do conteúdo não garanta a adesão e a escolha dos alimentos considerados saudáveis ou a exclusão do que foi por eles expressado como não saudável, o que pode até ter sido demonstrado por um dos estudantes de oito anos de idade, do $3^{\circ}$ ano, que, ao relatar alimentos que considerou como não saudáveis, o fez com os olhos fechados, como se estivesse tentando recordar o que foi abordado durante as práticas educativas.

Desenvolver conceitos de saúde com crianças pode não ter aplicação imediata, porém a correlação da alimentação adequada com a saúde poderá mostrar a importância de algumas escolhas futuras, quando esse indivíduo já tiver agregado outros conceitos que contribuirão em suas decisões. Embora a criança nem sempre faça a relação da prática alimentar com os benefícios à saúde, poderão permanecer com a ideia de que a nutrição é 
importante, de alguma forma, e com isso terão construído conceitos básicos para que, no futuro, quando tiverem mais conhecimentos, façam melhores escolhas (CONNORS, 2001).

\section{CONSIDERAÇÕES FINAIS}

A demonstração de interesse dos professores, sempre presentes nas atividades com suas turmas, provavelmente, estimulou a participação dos discentes.

Durante o lanche coletivo, a maioria dos alunos escolheu alimentos saudáveis, demonstrando apropriação do apresentado nas oficinas culinárias e nas gincanas, atividades que ocorreram anteriormente ao lanche coletivo.

O grupo focal possibilitou aos alunos a oportunidade de expor os conteúdos desenvolvidos durante as oficinas e as gincanas.

As turmas participantes do projeto obtiveram bom aproveitamento nas atividades lúdicas, no que diz respeito à participação e ao aprendizado.

Outros estudos devem ser desenvolvidos com a participação dos demais membros da comunidade escolar, de forma a conscientizá-los a respeito da importância da alimentação para a qualidade de vida.

\section{REFERÊNCIAS}

BIZZO, M. L. G.; LEDER, L. Educação nutricional nos parâmetros curriculares nacionais para o ensino fundamental. Rev. Nutr., Campinas, v. 18, n. 5, p. 661-667, out. 2005.

BRASIL. Ministério da Educação e Cultura. Parâmetros Curriculares Nacionais. Brasília, DF: MEC/SEF, 1997.

BRASIL. Ministério da Saúde. Escolas promotoras de saúde: experiências do Brasil. Brasília, DF: MS, 2006. (Série Promoção da Saúde).

BRASIL. Ministério da Saúde. Guia alimentar para a população brasileira. Disponível em: $<$ http://dtr2001.saude.gov.br/editora/produtos/livros/pdf/05_1109_M.pdf >. Acesso em: $11 \mathrm{dez}$. 2011.

CAMEJO, C. N. et al. Avaliação nutricional de escolares da rede pública de ensino do município de Bagé, Rio Grande do Sul. In: SALÃO INTERNACIONAL DE ENSINO, PESQUISA E EXTENSÃO-SIEPE, 4., Bagé. Anais... Bagé: UNIPAMPA, 2012.

CANESQUI, A. M. Pesquisas qualitativas em nutrição e alimentação. Rev. Nutr., Campinas, v. 22, n. 1, p. 125-139, fev. 2009.

CASTRO, I. R. R. et al. A culinária na promoção da alimentação saudável: delineamento e 
experimentação de método educativo dirigido a adolescentes e a profissionais das redes de saúde e de educação. Rev. Nutr., Campinas, v. 20, n. 6, p. 571-588, nov./dez. 2007.

CONNORS, P. et. al. Cafeteria factors that influence milk-drinking behaviors of elementary school children: grounded theory approach. J. Nutr. Educ., Denton, v. 33, n. 1, p. 31-36, jan.-fev. 2001.

COSTA, E. de Q.; RIBEIRO, V. M. B.; RIBEIRO, E. C. de O. Programa de alimentação escolar: espaço de aprendizagem e produção de conhecimento. Rev. Nutr., Campinas, v. 14, n. 3, p. 225-229, dez. 2001.

FERNANDES, I. C. B. Atividades lúdicas no desenvolvimento do processo de ensinoaprendizagem de discentes no âmbito escolar. 2012. 56 f. Trabalho de Conclusão de Curso (Graduação em Educação Física) - Faculdade de Educação Física, Universidade de Brasília. Brasília, 2012.

FREIRE, P. Pedagogia do oprimido. 50. ed. Rio de Janeiro: Paz e Terra, 2011.

FREITAS, M. do C. S. et al. Escola: lugar de estudar e de comer. Ciênc. Saúde Coletiva, Rio de Janeiro, v. 18, n. 4, p. 979-985, 2013.

GELLAR, L. A. et. al. Healthy eating practices: perceptions, facilitators, and barriers among youth with diabetes. Diabetes Educ., v. 3, n. 4, p. 671-679, jul.-ago. 2007

GOMES, M. E. S.; BARBOSA, E. F. A técnica de grupos focais para obtenção de dados qualitativos. 1999. Disponível em: <www.dppg.cefetmg.br/mtp/Tecnica\%20de20Grupos-\%20 Focaisdoc>. Acesso em: 18 jan. 2005.

HALLAL, P. C. et al. Prevalência de sedentarismo e fatores associados em adolescentes de 10-12 anos de idade. Cad. Saúde Pública, Rio de Janeiro, v. 22, n. 6, p. 1277-1287; jun. 2006.

IULIANO, B. A.; MANCUSO, A. M. C.; GAMBARDELLA, A. M. D. Educação nutricional em escolas de ensino fundamental do município de Guarulhos-SP. Mundo da Saúde, São Paulo, v. 33, n. 3, p. 264-272, 2009.

JANN, P. N.; LEITE, M. de F. Jogo do DNA: um instrumento pedagógico para o ensino de ciências e biologia. Ciências \& Cognição, Rio de Janeiro, v. 15, n. 1, p. 282-293, abr. 2010.

KELLY-SANTOS, A.; ROZEMBERG, B. Estudo de recepção de impressos por trabalhadores da construção civil: um debate das relações entre saúde e trabalho. Cad. Saúde Pública, Rio de Janeiro, v. 22; n. 5, p. 975-985, maio 2006.

MINAYO, M. C. de S. Desafio do conhecimento: pesquisa qualitativa em saúde. 7. ed. São Paulo: Hucitec: Abrasco, 2010.

PINTO, C. L.; TAVARES, H. M. O lúdico na aprendizagem: apreender e aprender. Revista da Católica, Uberlândia, v. 2, n. 3, p. 226-235, 2010.

RODRIGUES, E. M; BOOG, M. C. F. Problematização como estratégia de educação nutricional com adolescentes obesos. Cad. Saúde Pública, Rio de Janeiro, v. 22, n. 5, p. 923-931, maio 2006.

SALVI, C.; CENI, G. C. Educação nutricional na infância: metodologias de aplicação. In: 
FÓRUM NACIONAL EM SAÚDE, 2., SALÃO CIENTÍFICO DAS CIÊNCIAS DA SAÚDE: CAMINHOS DA INTERDISCIPLINARIDADE, 1., 2009, Erechim. Anais... Rio Grande do Sul: Erechim, 2009, p. 1-8.

SILVA, M. X. Nutrição escolar consciente: oficinas de culinária para alunos das escolas públicas de Duque de Caxias-RJ. 2010. Dissertação (Mestrado em Nutrição) - Universidade Federal do Rio de Janeiro, Rio de Janeiro, 2010.

SILVERMAN, D. Interpretação de dados qualitativos: métodos, análise de entrevistas, textos e interações. Tradução de Magda França Lopes. 3 ed. Porto Alegre: Artmed, 2009.

STEVENSON, C. et al. Adolescents' views of food and eating: identifying barriers to health yeating. Journal of Adolescence, London, v. 30, n. 3, p. 417-434, june 2007.

SUÑE, F. R. et al. Prevalência e fatores associados para sobrepeso e obesidade em escolares de uma cidade no Sul do Brasil. Cad. Saúde Pública, Rio de Janeiro, v. 23, n. 6, p. 1361-1371, jun. 2007.

TCHAKMAKIAN, L. A. A alimentação na promoção da saúde em idosos hipertensos: testando uma nova técnica. 2002, 200f. Dissertação (Mestrado em Gerontologia) - Pontifícia Universidade Católica de São Paulo, São Paulo, 2002.

TORAL, N.; CONTI, M. A.; SLATER, B. A alimentação saudável na ótica dos adolescentes: percepções e barreiras à sua implementação e características esperadas em materiais educativos. Cad. Saúde Pública, Rio de Janeiro, v. 25, n. 11, p. 2386-2394, nov. 2009.

Submetido em 16 de julho de 2012.

Aprovado em 24 de junho de 2013. 


\title{
EDUCAÇÃO NUTRICIONAL PARA PRÉ-ESCOLARES: UMA FERRAMENTA DE INTERVENÇÃO
}

\author{
Mônica Cristina Lopes do Carmo ${ }^{1}$ \\ Luiza Carla Vidigal Castro ${ }^{2}$ \\ Juliana Farias de Novaes ${ }^{3}$
}

\begin{abstract}
RESUMO: A faixa etária pré-escolar caracteriza-se por um período de alta vulnerabilidade e susceptibilidade à má nutrição. Nesta fase, as carências nutricionais levam a um crescimento deficiente, aumento do risco de infecções; alterações no processo de maturação do sistema nervoso e no desenvolvimento mental e intelectual, provocando desequilíbrios funcionais. O presente artigo tem como objetivo traçar o perfil nutricional de pré-escolares em nove Núcleos Comunitários do município de Viçosa-MG, promovendo, neste período, a melhoria do estado nutricional por meio de educação nutricional. A metodologia utilizada caracteriza-se pela avaliação antropométrica, em que se aferiram peso e estatura para posterior análise dos índices (P/I), (P/E) e (E/I). Os resultados representam a avaliação de 155 pré-escolares antes da intervenção: 91,61\% $(n=142)$ das crianças apresentaram estado nutricional de eutrofia, 7,09\% $(\mathrm{n}=11)$ apresentaram sobrepeso, $1,29 \%(n=2)$ apresentaram baixo peso. Após a intervenção foi avaliado o estado nutricional de 95 crianças, com o seguinte diagnóstico: $94 \%(n=89)$ crianças eutróficas, $1 \%(n=1)$ crianças com baixo peso e $5 \%(n=5)$ crianças com sobrepeso. Portanto, é possível observar que a participação da comunidade escolar e a adequada formação de agentes envolvidos nos procedimentos de Segurança Alimentar para as Unidades de Alimentação e Nutrição Escolar são indispensáveis para a prática promotora de saúde de crianças institucionalizadas que recebem a merenda escolar.
\end{abstract}

PALAVRAS-CHAVE: Pré-escolares. Educação nutricional. Avaliação antropométrica. Creche.

Nutrition education for preschool: a tool for action

\begin{abstract}
The preschool age is characterized by a period of high vulnerability and susceptibility to malnutrition. In this phase, nutritional deficiencies lead to growth deficiency, increase of infection risk, changes in the maturation of the nervous system, mental and intellectual development, causing functional imbalances. This paper goals to trace the nutritional status of preschoolers in 9 Community Centers of the city Viçosa in the state of Minas Gerais, promoting, during this period, through nutrition education, improvement of nutritional status. Anthropometric evaluation has measured the weight and height for later analysis of the indexes $(\mathrm{P} / \mathrm{I}),(\mathrm{P} / \mathrm{E})$ and $(\mathrm{E} / \mathrm{I})$. The results represent the evaluation of 155 preschool before the intervention: $91.61 \%(\mathrm{n}=142)$ of the children had nutritional status of eutrophy, $7.09 \%(n=11)$ of them were overweight and $1.29 \%(n=2)$ were underweight. After the intervention, it was assessed the nutritional status of 95 children with the following diagnosis: 94\% $(n=89)$ eutrophic children, $1 \%(n=1)$ were underweight and $5 \%(n=5)$ were overweight

\footnotetext{
${ }^{1}$ Mestranda em Ciências da Nutrição e do Esporte e Metabolismo pela Universidade Estadual de Campinas (monica.carmo@ufv.br).

${ }^{2}$ Doutora em Ciência e Tecnologia de Alimentos pela Universidade Federal de Viçosa, professora no curso de Nutrição da Universidade Federal de Viçosa (luiza.castro@ufv.br).

${ }^{3}$ Doutora em Ciências da Saúde pela Universidade Federal de Minas Gerais, professora no curso de Nutrição da Universidade Federal de
} Viçosa (jnovaes@ufv.br).
\end{abstract}

